This is an open access article under the CC BY-NC-ND license

Issue IV, 22 November 2021

e-ISSN 2707-9481

Institute of Metallurgy and Ore Beneficiation, Satbayev University, Almaty, Kazakhstan

ISBN 978-601-323-252-2 https://doi.org/10.31643/2021.05

\author{
Aisha Tastanova \\ Satbayev University, Institute of Metallurgy \\ and Ore Beneficiation, Kazakhstan \\ E-mail: a.tastanova@stud.satbayev.university \\ ORCID ID 0000-0003--1953-8938 \\ Gulnar Abdykirova \\ Satbayev University, Institute of Metallurgy \\ and Ore Beneficiation, Kazakhstan \\ E-mail: g.abdykirova@satbayev.university \\ ORCID ID 0000-0001-5956-4730
}

\author{
Saniya Temirova \\ Satbayev University, Institute of Metallurgy \\ and Ore Beneficiation, Kazakhstan \\ E-mail: s.temirova@satbayev.university \\ ORCID ID 0000-0003-3039-2546 \\ Alla Biryukova \\ Satbayev University, Institute of Metallurgy \\ and Ore Beneficiation, Kazakhstan \\ E-mail: a.biryukova@satbayev.university \\ ORCID ID 0000-0001-6797-7471
}

\title{
Processing and production of pellets from poor-grade manganese- containing raw materials
}

\begin{abstract}
The variety of manganese minerals caused by the valent state of metal in compounds is demonstrated. Different processing methods for manganese-containing mineral and technogenic raw materials are considered. The process of extraction of manganese from ferruginous manganese ore using reduction roasting and magnetic separation, beneficiation technology of poor-grade manganese ore to improve the ratio of $\mathrm{Mn} / \mathrm{Fe}$; processes of beneficiation and sintering of fine ferruginous manganese ore with low manganese content; production of agglomerate from the concentrate of manganese poor-grade ore to produce ferrosilicon manganese are described. Results of the authors researches intended to obtain concentrate from manganese-containing sludge and to produce hardened pellets suitable for melting into ferromanganese on its basis using a new component of the binder are presented.
\end{abstract}

Keywords: poor quality manganese raw materials, beneficiation methods, manganese concentrate, agglomeration, manganese pellets

Cite this article as: Tastanova A.; Abdykirova G.; Temirova S.; Biryukova A.; (2021). Processing and production of pellets from poor-grade manganese-containing raw materials. Challenges of Science. Issue IV, 2021, pp. 35-39. https://doi.org/10.31643/2021.05

Increased demand for manganese alloys and compounds for various industries drives the need to develop and improve manganese beneficiation technologies, including poor-grade manganese ores

World manganese resources are divided into three main categories: oxide, siliceous, and carbonate ores under beneficiation characteristics [1]. The choice of the appropriate beneficiation process depends on the gangue minerals and their association. The gravity separation techniques are applied to siliceous ores and are used industrially in India and Brazil. Iron minerals are always present as impurities in all types of manganese ores; however, they are successfully removed via various magnetic separation processes. Carbonate ores are mainly found in Ukraine, China, and South Africa, and these ores are enriched mainly by gravity and magnetic separation. The type of ore also plays an important role in the alloying process.

Due to the decreasing resources of rich manganese ores [2], the use of poor-grade ores and technogenic raw materials in industrial processes is of great importance nowadays. Fine-grained raw materials with low manganese content and manganese-containing tailings result from mining, crushing, and beneficiation of ores with high manganese content.

Manganese is an important alloying element in the production of special alloys and is also used for sulphur fixing and as a deoxidant in the traditional production of carbon steel [3]. 
Manganese oxide, silicate, and carbonate ores are mainly mined as raw materials for steel production where $\mathrm{Mn}$ is mainly added as ferroalloys (approximately $90 \%$ ) but they are also used for the production of batteries and to a lesser extent for the production of fertilizers and pigments. Increased consumption of manganese and its compounds has led to increased production of manganese.

The raw material mined as a raw material for blast furnaces or arc furnaces and sometimes for sintering or pelletizing is often manganese oxide, but manganese silicate and manganese carbonate minerals are also present in significant concentrations. The mineral and chemical compositions of manganese ore are complex in composition and texture as manganese can be present in a divalent, trivalent, or quadrivalent state. In addition, manganese minerals include other elements (e.g. $\mathrm{K}, \mathrm{Na}, \mathrm{Fe}, \mathrm{Mg}, \mathrm{Al}, \mathrm{Si}$, and $\mathrm{Ba}$ ) (Table 1).

Table 1. List of common Mn minerals and their composition (formed by the predominant valent state of $\mathrm{Mn}$ )

\begin{tabular}{|c|c|}
\hline Mineral & Formula \\
\hline Pyrolusite & $\beta-\mathrm{MnO}_{2}$ \\
\hline Ramsdellite & $\mathrm{v}-\mathrm{MnO}_{2}$ \\
\hline Nsutite & $\left.\left(\mathrm{Mn}^{4+}\right)\right)_{(1-x)}\left(\mathrm{Mn}^{2+}\right) \mathrm{O}_{(2-2 x)}\left(\mathrm{OH}_{2 x}\right.$ \\
\hline Hollandite & $\mathrm{Ba}\left(\mathrm{Mn}^{4+}{ }_{6}, \mathrm{Mn}^{3+}{ }_{2}\right) \mathrm{O}_{16}$ \\
\hline Coronadite & $\mathrm{Pb}\left(\mathrm{Mn}^{4+}{ }_{6}, \mathrm{Mn}^{3+}{ }_{2}\right) \mathrm{O}_{16}$ \\
\hline Cryptomelane & $\mathrm{K}\left(\mathrm{Mn}^{4+} 7, \mathrm{Mn}^{3+}\right) \mathrm{O}_{16}$ \\
\hline Manjiroite & $\mathrm{Na}\left(\mathrm{Mn}^{4+} 7, \mathrm{Mn}^{3+}\right) \mathrm{O}_{16}$ \\
\hline Romanecite & $\left(\mathrm{Ba}, \mathrm{H}_{2} \mathrm{O}\right)_{2}\left(\mathrm{Mn}^{4+}, \mathrm{Mn}^{3+}\right)_{5} \mathrm{O}_{10}$ \\
\hline Vernadite & $\left(\mathrm{Mn}^{4+}, \mathrm{Fe}^{3+}, \mathrm{Ca}, \mathrm{Na}\right)(\mathrm{O}, \mathrm{OH})_{2} \cdot \mathrm{n}\left(\mathrm{H}_{2} \mathrm{O}\right)$ \\
\hline Byrnessite & $(\mathrm{Na}, \mathrm{Ca}) 0,5\left(\mathrm{Mn}^{4+}, \mathrm{Mn}^{3+}\right)_{2} \mathrm{O}_{4} \cdot 1,5\left(\mathrm{H}_{2} \mathrm{O}\right)$ \\
\hline Hydrohetaerolite & $\left(\mathrm{Zn}, \mathrm{Fe} 2^{+}, \mathrm{Mn}^{2+}\right)\left(\mathrm{Mn}^{4+}\right)_{3} \mathrm{O}_{7} \cdot 3 \mathrm{H}_{2} \mathrm{O}$ \\
\hline Lithiophorite & $(\mathrm{Li}, \mathrm{Al}) \mathrm{Mn}^{4+} \mathrm{O}_{2}(\mathrm{OH})_{2}$ \\
\hline Manganite & $\mathrm{\gamma}-\mathrm{Mn}^{3+} \mathrm{OOH}$ \\
\hline Brownite-I & $\left(\mathrm{Mn}^{2+}, \mathrm{Mn}^{3+}\right)_{6}\left(\mathrm{SiO}_{4}\right) \mathrm{O}_{8}$ \\
\hline Brownite- II & $\mathrm{Ca}\left(\mathrm{Mn}^{3+}, \mathrm{Fe}^{3+}\right)_{6}\left(\mathrm{SiO}_{4}\right) \mathrm{O}_{8}$ \\
\hline Bixbyite & $\left(\mathrm{Mn}^{3+}, \mathrm{Fe}^{3+}\right)_{2} \mathrm{O}_{3}$ \\
\hline Marokite & $\mathrm{CaMn}^{3+}{ }_{2} \mathrm{O}_{4}$ \\
\hline Hausmannite & $\mathrm{Mn}^{2+}\left(\mathrm{Mn}^{3+}\right)_{2} \mathrm{O}_{4}$ \\
\hline lacobsite & $\left(\mathrm{Mn}^{2+}, \mathrm{Fe}^{2+}, \mathrm{Mg}\right)\left(\mathrm{Fe}^{3+}, \mathrm{Mn}^{3+}\right)_{2} \mathrm{O}_{4}$ \\
\hline
\end{tabular}

The degree to which impurities of other elements in manganese ore minerals influence their microhardness is difficult to assess because microhardness data for common manganese ore minerals usually do not include relevant information on their chemical composition.

The physical, mineralogical, and textural properties of manganese ore minerals are known to influence their thermal properties and hence their high-temperature behavior during agglomeration or alloy production.

Manganese minerals are often interchanged or closely intergrown on a micron-scale (e.g. nsutite and cryptomelane), therefore knowledge of the chemical composition of minerals, the texture of minerals, and the nature of intergrowth of small minerals is necessary to determine the processing of manganese raw materials.

As a rule, ores with a manganese content of more than $30 \%$ and a manganese/iron ratio of more than 5 are required for the production of manganese alloys. Ores with low manganese content $(\approx 12 \%$ and less) can be used in the production of manganese cast irons. 
Due to the decrease of rich manganese ores (> $30 \% \mathrm{Mn}$ ), attempts have been made to use poorgrade siliceous manganese ores to produce SiMn alloys. In addition, many countries such as China, India, and Russia do not have ores with high manganese content.

In the production of SiMn alloy, silica manganese ores are first reduced with carbon in a blast furnace with an operating temperature range of $1250-1350{ }^{\circ} \mathrm{C}$ to remove the iron component due to the melting difference between the manganese silicate slag and the iron slurry.

Roasting followed by magnetic separation is used to increase the $\mathrm{Mn} / \mathrm{Fe}$ ratio in poor-grade manganese ores. The magnetic separation process requires more advanced and expensive equipment, but has advantages such as ease of use, environmental compatibility, and low further operating costs.

In the roasting process, the manganese oxide and iron oxide are reduced in stages to $\mathrm{MnO}$ and $\mathrm{Fe}$ respectively. When magnetic separation is used, products can be enriched to produce magnetic concentrate and non-magnetic residue, respectively.

Research on manganese ores has mainly focused on the recovery of manganese by metallurgical methods. In developing methods of complex utilization of ferruginous manganese ores it has been found that crystalline substitution of Fe and Mn can easily occur between manganese and iron oxides, forming spineltype manganese ferrite with strong magnetism.

The influence of mineralogy on the magnetic separation of manganese minerals has been described, while data on manganese beneficiation using dry magnetic separation from ferrous manganese ore (poorgrade high iron-manganese ores) is limited.

Numerous studies have been conducted on the use of electrolytic manganese residues (EMR) [4]. The effective use of electrolytic manganese residue (EMR) resources can not only bring environmental and social benefits but also economic benefits from the operation of electrolytic manganese residue (EMR) facilities.

In terms of catalytic activity, the most promising mineral manganese oxide is cryptomelane, which has been the subject of some fundamental research in recent years. The versatility of cryptomelane-based materials is due to their high porosity, acidity, hydrophobicity, electronic and ionic conductivity, as well as easy removal of lattice oxygen and reduction ability.

Thus, low Fe and $\mathrm{Mn}$ iron-manganese ores can be concentrated using mineral separation techniques such as physical separation, including gravity, washing, magnetism, flotation and leaching, smelting, and carbothermal reduction roasting followed by magnetic separation or acid leaching. In addition to the carbothermal reduction firing that has been used in recent decades, the reduction behavior of $\mathrm{Fe}$ and $\mathrm{Mn}$ oxides exposed to reducing agents such as solid and gaseous reductants $\left(\mathrm{CO}, \mathrm{H}_{2}, \mathrm{CH}_{4}\right.$, graphite, coke, biomass, coal).

A study [5] presented the results of microhardness tests on manganese ore minerals from several different types of manganese ores with different mineralogical properties and textures. The data obtained show that there is a clear relationship between mineral microhardness and porosity, microcrystallinity from micro- to nanometres, resulting in large variations in microhardness for some common manganese ore minerals. For example, cryptomelane with lower reflectivity and higher nano- and microporosity has a significantly lower microhardness (average $267 \mathrm{~kg} / \mathrm{mm}^{2}$ ) than cryptomelane with higher quality reflectivity (average $629 \mathrm{~kg} / \mathrm{mm}^{2}$ ).

This study showed that microhardness of important and common manganese ore minerals is not only a factor determining mineral properties such as mineral type and crystal structure but also properties that vary within a mineral - crystallinity, crystal size, and micro- and nanoporosity of an individual mineral crystal. Furthermore, micro-hardness affects the extent to which certain phases can affect the behavior at high temperatures and the tolerable moisture limit during bulk transport of fine-grained ore due to differences in the water-holding capacity of different minerals and different forms of the same mineral.

The microhardness of manganese ore phases can be used in combination with physical testing methods to better determine the relationship between mineral and ore particle texture types and porosity, the permeability of the bulk sample. An integrated approach to determine the relationship between mineral (particle) texture, microhardness, and process characteristics such as CO reduction reactivity in an electric furnace has been proposed.

In [6] beneficiation of two different Indonesian low-grade manganese ores was carried out by gravity separation and reduction roasting followed by magnetic separation to improve their $\mathrm{Mn} / \mathrm{Fe}$ ratio. The effect of particle size and reductive roasting temperature in the beneficiation process was determined. X-ray 
fluorescence and X-ray phase analysis methods were used to characterize poor-grade manganese ores and beneficiation products. It was found that manganese oxide in the form of pyrolusite $\left(\mathrm{MnO}_{2}\right)$ is easier to enrich with increasing $\mathrm{Mn} / \mathrm{Fe}$ ratio than in the form of pyroxmangite $\left(\mathrm{MnSiO}_{3}\right)$ and grossular manganese $\left(\mathrm{Ca}_{1,3} \mathrm{Mg}_{0,1} \mathrm{Mn}_{0,8} \mathrm{Fe}_{0,8} \mathrm{Al}_{2}\left(\mathrm{SiO}_{4}\right)_{3}\right.$. At optimal conditions of beneficiation of poor-grade manganese ore reduction roasting at $700{ }^{\circ} \mathrm{C}$ followed by magnetic separation process - an increase of $\mathrm{Mn} / \mathrm{Fe}$ ratio from 1.39 to 4.0 was achieved.

Poor-grade iron-containing manganese ore is a potential source of solid waste. In a study [7], a reductive slurry roasting and magnetic separation (SRMS) technique was used to treat iron-bearing manganese ore for complex extraction of iron and manganese. The phase transformation of minerals during roasting was investigated using an X-ray diffraction analyzer (XRD) and a high-resolution transmission electron microscope (HRTEM). At optimal conditions - reduction temperature $680^{\circ} \mathrm{C}$, reduction time $30 \mathrm{~min}$, CO concentration $20 \%$, particle size $0.9 \mathrm{~mm}$ obtained iron concentrate with the iron content of $67.38 \%$ and recovery rate of $87.14 \%$ and manganese concentrate with a manganese content of $30.51 \%$ and recovery rate of $87.02 \%$. Magnetite converted from hematite was enriched into magnetic separation concentrate and manganosite converted from pyrolusite and brownite into magnetic separation tailings. SRMS allows full use of the iron-bearing manganese without residue.

Studies on characteristics of beneficiation and agglomeration have been carried out to develop a strategy to use the typical Indian fine-grained manganese ore [8-10]. The main mineral phases detected are pyrolusite, hematite, goethite, clay, feldspar, and quartz. QEMSCAN and Sink-Float studies have shown that $40 \%$ of the manganese minerals are in liberated form, while $30 \%$ are associated with iron minerals. Classification followed by a two-stage high-intensity magnetic separation process (1.7 and 1.1 Tesla) resulted in 35-40 \% ferromanganese material with 47-49 \% Mn recovery. The material was briquetted with molasses $(7 \%)$, cement $(3 \%)$, and bentonite $(1 \%)$. The resulting sinter is suitable for use in smelting furnaces in metallurgy. An economically efficient technological scheme has been developed.

The paper [11] discusses the production of agglomerate from poor manganese ore concentrate for the production of ferrosilicon manganese. It was discovered that the chemical composition of Jezda concentrate used in ferrosilicon manganese production was 30-32 \% $\mathrm{Mn}$ and $28-30 \% \mathrm{Si}$. The optimum rate of coke fines during sintering was $9 \%$.

We studied the beneficiation of technogenic manganese-containing raw materials with coarseness less than $5 \mathrm{~mm}$. It was found that the main valuable minerals of the feedstock are psilomelane, pyrolusite, bementite; among the rock-forming minerals, quartz and kaolinite, often saturated with fine iron compounds, predominate.

Beneficiation of manganese sludge of particle size class $-0,071+0 \mathrm{~mm}$ on a laboratory concentrator table was carried out. The possibility of obtaining fine manganese concentrate with a manganese content of $28.57 \%$ and iron content of $10.69 \%$ with recovery $68,5 \%$ and $72,37 \%$, accordingly. Manganese pellets were produced from the obtained manganese concentrate with grain size less than $2.5 \mathrm{~mm}$ using a new binder component - natural material.

The results of X-ray phase analysis of manganese-containing pellets fired at $1150{ }^{\circ} \mathrm{C}$ showed that when kaolin is used as a binder, phases of jacobsite, ulvöespinel, ferrian, and ferrous bustamite are formed in the charge during firing. The ulvöespinel, ferrian is a complex spinel phase. Appending a new binder natural material into the charge somewhat changes the phase composition of the firing product and contributes to the formation of the following phases: jacobsite, bustomite, instead of spinel phase appears hedenbergite pyroxene of complex composition. The combined appending of a high-iron binding agent and lime increases the content of jacobsite to $84.4 \%$, whereby only two phases are formed: an oxidized form of manganeseiron compound (jacobsite) and complex hedenbergite. The pellets produced are suitable for further metallurgical processing - smelting into ferromanganese.

To sum up, the results of studies by foreign and Kazakh authors have shown the possibility of processing low-quality manganese-containing raw materials using new technological solutions.

Cite this article as: Tastanova A.; Abdykirova G.; Temirova S.; Biryukova A.; (2021). Processing and production of pellets from poor-grade manganese-containing raw materials. Challenges of Science. Issue IV, 2021, pp. 35-39. https://doi.org/10.31643/2021.05 


\section{References}

1. Veerendra Singh, Tarun Chakraborty, Sunil K Tripathy; (2020). A Review of Low Grade Manganese Ore Upgradation Processes. Mineral Processing and Extractive Metallurgy. Review. (6) 41, 417-438. https://doi.org/10.1080/08827508.2019.1634567

2. Bingbing Liu, Yuanbo Zhang, Manman Lu, Zijian Su, Guanghui Li, Tao Jiang; (2019). Extraction and separation of manganese and iron from ferruginous manganese ores: A review. Minerals Engineering. (131), 286-303.

https://doi.org/10.1016/j.mineng.2018.11.016

3. Michael John Peterson, Sarath Hapugoda; (2020). Microhardness characterisation of manganese ore minerals Implications for downstream processing. Minerals Engineering. (157), No. 106537.

https://doi.org/10.1016/j.mineng.2020.106537

4. Dejun He, Jiancheng Shu, Rong Wang, Mengjun Chen, Rui Wang, Yushi Gao, Renlong Liu, Zuohua Liu, Zhonghui Xu, Daoyong Tan, Hannian Gu, Ning Wang; (2021). A critical review on approaches for electrolytic manganese residue treatment and disposal technology: Reduction, pretreatment, and reuse. Journal of Hazardous Materials. (418), No. 126235.

https://doi.org/10.1016/j.jhazmat.2021.126235

5. Michael John Peterson, Sarath Hapugoda; (2020). Microhardness characterisation of manganese ore minerals Implications for downstream processing. Minerals Engineering. (157), No. 106537.

https://doi.org/10.1016/j.mineng.2020.106537

6. Nurjaman F., Amarela S., Noegroho A., Ferdian D., Suharno B.; (2017). Beneficiation of two different low-grade Indonesian manganese ores to improve the Mn/Fe ratio. AIP Conference Proceedings. (1823) 1, No 020021.

https://doi.org/10.1063/1.4978094

7. Shuai Yuan, Wentao Zhou, Yuexin Han, Yanjun Li; (2020). An innovative technology for full component recovery of iron and manganese from low grade iron-bearing manganese ore. Powder Technology. (373), 73-81.

https://doi.org/10.1016/j.powtec.2020.06.032

8. Veerendra Singh, Tamal K.Ghosh, Y. Ramamurthy, Vilas Tathavadkar; (2011). Beneficiation and agglomeration process to utilize low-grade ferruginous manganese ore fines. International Journal of Mineral Processing. (99) 1-4, 84-86.

https://doi.org/10.1016/j.minpro.2011.03.003

9. Kenzhaliyev B.K., Imangalieva L.M., Manapova A.I., Azlan M.N. (2021). Kaolinite clays as a source of raw materials for the aluminum industry of the Republic of Kazakhstan. Kompleksnoe Ispol'zovanie Mineral'nogo Syr'a = Complex Use of Mineral Resources. Volume 4, Issue 319, pp. 5-12. https://doi.org/10.31643/2021/6445.34

10. Kuldeev E.I., Bondarenko I.V., Temirova S.S. Promising ways to increase raw material base of the chrome industry of the metallurgical industry of the Kazakhstan. Kompleksnoe Ispol'zovanie Mineral'nogo Syr'a = Complex Use of Mineral Resources. 2020. - №2 (313). - p. 64-70. https://doi.org/10.31643/2020/6445.19

11. Dmitriev A.N., Solomakhin A.V., Kashin V.V., Verushkin V.V.; (2003). Making sinter from concentrate of low-grade manganese ore for use in the production of ferrosilicomanganese. Metallurgist. (47) 3-4, 99-103.

https://doi.org/10.1023/A:1024982325310 